\title{
Literatura Inca (¿indígena?) como representación de la literatura peruana
}

\author{
GonZalo Espino Relucé \\ Departamento de Literatura
}

$\mathrm{E}$ sta comunicación propone la relación entre las bellas letras y las manifestaciones discursivas vinculadas al indio; por eso, esboza las principales ideas literarias que Jorge Basadre propone en Equivocaciones y cuyo trazo se puede leer en Historia de la República del Perú. ${ }^{1}$ Se detiene en la importancia de la Literatura inca, compilación de Basadre, cuya publicación constituye un recuento de la literatura prehispánica, la producción colonial y republicana de la escritura literaria quechua como representación de lo indígena para las culturas peruanas. Lo vinculo, asimismo, a la comprensión de la literatura como ejercicio heterogéneo y a las formas como el indio es representado en la escritura a finales de la primera mitad del siglo XX.

La última publicación de Dedo Crítico recuerda la actualidad de Basadre para el pensamiento literario del país. La encuesta presentada por esta publicación destaca dos textos, Equivocaciones e Historia de la República del Perú. Los críticos que respondieron al formulario, olvidaron, en mi opinión, dos libros clave: Tarmap Pacha-Huaray (1905) de Adolfo Vienrich y Literatura Inca (1938) de Jorge Basadre. ${ }^{2}$ Los estudios literarios en el Perú en realidad toman cuerpo recién en la segunda mitad del siglo XX. Los trabajos de Basadre se ubican en esa gama de aproximaciones a la cultura y, seguramente, con una preocupación por reportar la diversidad nacional. En líneas generales, Jorge Basadre es un intelectual atento a lo que ocurre en el mundo de la cultura y de la literatura. Está a la caza del dato preciso que en imágenes felices hacen de su monumental

Este trabajo fue presentado como ponencia en el Coloquio Interdisciplinario: Repensando la República. Las huellas de Jorge Basadre 1903-2003 realizado en Lima entre el 4 y 5 de diciembre de 2003, organizado por la Comisión Organizadora del Centenario de Jorge Basadre - Universidad Nacional Mayor de San Marcos.

2 Cf. «Los mejores libros de la crítica literaria peruana del siglo XX», Dedo Crítico N. ${ }^{\circ} 9$ (2002). 
trabajo un texto próximo a la novela. La inclusión de la literatura en sus reflexiones tiene como objeto completar el cuadro histórico, dar cuenta de las tendencias en general o aportar una mirada sobre un tema en debate como el indio.

\section{LAS IDEAS DE BASADRE}

Las intuiciones de Basadre están alimentadas por esa trama cosmopolita y la actitud de un lector atento a la agenda cultural de la época. No hay que olvidar que Basadre se convierte en un entusiasta de las revueltas del 18 y el 26, y consideraba que «el crítico sereno debe actuar con precipitación» (Basadre XIV: 3511). Si bien podríamos pecar de esquemáticos, identificamos cuatro ideas básicas que organizan su reflexión en torno a la literatura: a) La literatura como proceso. Asume el «largo plazo» como diseño temporal y la vincula a la categoría «generación»; b) En ese contexto la literatura peruana alimenta el reto de lo nuevo. La «conmoción social» será uno de los elementos inspiradores de la literatura peruana, de ella se desprenden las tendencias vigentes; c) Valora la obra y el autor que vincula a los contextos socioculturales, locales y a su relación con la producción discursiva extranjera; d) La lectura que realiza intenta recuperar los procesos regionales. La provincia tiene especial atención en Basadre y su balance incluye su relación con las tendencias ecuménicas.

Estas ideas se organizan en torno a las prácticas literarias del período y tienen que ver con el debate sobre la literatura peruana de inicios del siglo XX. José de la Riva-Agüero, José Gálvez, Luis Alberto Sánchez y José Carlos Mariátegui ${ }^{3}$ elaboran una red textual sobre la literatura nacional, inaugurando un discurso sobre los imaginarios sociales de lo nacional en la literatura, signado por su afluencia positivista que ve en el medio y la raza modalidades de representación. Se piensa, por entonces, en una literatura hecha fundamentalmente por letrados, por quienes accedieron a la palabra escrita; ciertamente, se vislumbraba sobre el destino de la palabra — para usar la metáfora del maestro León-

3 Un recuento del debate puede examinarse en el trabajo de Miguel Ángel Rodríguez REA, La literatura peruana en debate: 1905-1928 (Lima, Ed. Antonio Ricardo, 1985. 2. ${ }^{\text {da }}$ ed. Lima, Universidad Ricardo Palma, 2002). 
Portilla - si ésta debiese representar a los criollos o a los indios. Es obvio que en este contexto no se incorporan a las otras literaturas, pues no eran asumidas como bellas letras sino como folclor. Las publicaciones que se suceden de la otra literatura se las asocia a formas primitivas y no alcanzan mérito sino a costa de ser imaginadas como de las clases subalternas o de las tribus retardatarias del país. Sólo si éstas son trasladadas a formatos autorizados y de circulación en la literatura convencional de la época serán recepcionadas. La voz de Adolfo Vienrich resulta marginal, solitaria, no sólo porque para el período no se aceptaba a los indios con posibilidades civilizatorias, sino porque se la confundía con lo que en el XIX se decía: la voz del indio es como la voz del inca. El mérito del trabajo de Vienrich es exactamente ese.

\section{LiTERATURA INCA}

Las publicaciones sobre literatura quechua escrita o aquellas que representan las formas verbales indígenas se configuran como formas discursivas vinculadas a la emoción social, por eso tienen expresión en lo que se llamó por entonces serranismo y en lo que se desarrolló como indigenismo, sobre todo en el Sur andino. Tales formas no siempre representaban la actualidad del hombre andino, sino un pasado aristocrático, tampoco necesariamente garantizaban la voz india. Una de estas formas fue declarar y confundir a la cultura indígena como cultura inca, con lo cual lo que se ofrecía era una lectura aristocrática del indio y su cultura. Se la prestigiaba, pero no se la acepta en su sentido emergente, sublevante y presente.

Este tipo de publicaciones no sólo tenían escasa circulación, eran de difícil acceso, pues correspondían a eso que he llamado la aldea letrada quechua. ${ }^{4}$ Casi todas ellas corresponden a lo que Ventura García Calderón llama «rareza bibliográfica ${ }^{5}$ a propósito de Tarmap Pacha Huaray. Sea porque las ediciones

\footnotetext{
$4 \quad$ Cf. Espino Relucé, Gonzalo: «La aldea letrada quechua: Literatura quechua en el espacio de la literatura canónica del siglo XIX» en Escritura y Pensamiento N. ${ }^{\circ} 8$ (2001) y «La literatura peruana del siglo XIX y la aldea letrada quechua» en Ajos \& Zafiros, N. ${ }^{\circ} 5$ (2003). Literatura Inca. Nota de Ventura García CALDERón, p.106.
} 
tuvieron lugar en el exterior, porque tales impresos escasamente llegaron a las ciudades andinas y difícilmente circulaban en la ciudad letrada. El curso de tales publicaciones, por lo demás, resultaba exótico; es decir, un reconocimiento de país extraño, curioso y con formas primitivas que supervivían para entonces.

Esto también se explica porque las más importantes investigaciones sobre la literatura quechua escrita de la Colonia y la República tuvieron lugar en Alemania, Francia e Inglaterra. Una muestra de ello es el debate ollantino y el conjunto de estudios sobre la cultura quechua y aimara. Así, libros inaugurales como Antigüedades peruanas de Mariano de Rivero y J. Tschudi, o el estudio sobre Ollanta de Tschudi, se publican en Viena. Los trabajos de E. W. Middendorf Dramatische un Lyrishe Dichtungen der Keshua-Sprache (1891) y Ollanta, ein Drama der Keshuasprache (1896) fueron editados en Leipzig. Raoul y Marguerite Harcourt publican en París La musique des Incas et ses survivances (1925).

En el mismo sentido, libros como la Civilización del Indio de Carlos Felipe Beltrán se imprime en Oruro (1880) y en Cuzco (1888). Lo propio ocurre con esa bibliografía casi inhallable, me refiero a León Mera, Cantares del pueblo ecuatoriano (1892) o trabajos como el de Marcos Jiménez de la Espada, Colección de Yaravies quiteños presentado en Madrid (1883). A mediados de siglo aparece un recuento de ese estado de cosas en el monumental trabajo Bibliographie des langues Aymará et Kicua 1540-1875 de Paúl Rivet y Georges de Créqui-Montfort editado en París (1951-1952).

La virtud del libro de Jorge Basadre está precisamente en haber recopilado la mejor bibliografía, la más potable, y poner a disposición del lector una de las antologías más completas de los textos quechuas e indígenas. Como libro Literatura inca define un ciclo de las otras literaturas al incorporar la producción textual quechua que va de 1905 a 1937. Será, pues, entre 1905 y 1980, la Antología completa y la más actualizada porque logra concentrar y exponer los textos más representativos hasta entonces dispersos. ${ }^{6}$

Si consideramos que Tarmap Pacha-Huaray (1905) y Literatura inca (1938) representa dos momentos, un tercer momento de síntesis estará representado por la compilación de Edmundo Bendezú, Literatura quechua (1980). 


\section{¿LITERATURA QUECHUA?}

La categoría literatura inca resulta una escritura exótica, porque exactamente remite al pasado prestigiado, pero no al actual. Pero, ¿cuáles son las ideas que tiene Basadre sobre la literatura inca? Para una explicación del pensamiento del historiador vamos a recordar el ensayo «En torno a la literatura quechua» (1939) publicado en Sphinx. ${ }^{7}$ Aunque debe añadirse que existe una suerte de memoria no escrita, en la que se suele decir que cuando Ventura García Calderón había concluido el diseño de su Biblioteca de la Cultura Peruana, alguien le sugirió que debía haber un volumen dedicado al pasado prehispánico. No habiendo candidatos, solicitó que le recomendaran algunos, entre éstos, estuvo la propuesta de encargar la preparación del libro a Jorge Basadre. El historiador preparó la compilación que ahora conocemos, pero para sorpresa de éste, el Prólogo que había elaborado no apareció en la edición de 1938. Sólo tenemos la armazón de lo que examina como literatura inca. El pórtico de la antología que había preparado para la Biblioteca de la Cultura Peruana, un año después de la publicación del libro, aparece convertido en ensayo en la revista sanmarquina Sphinx.

«En torno a la literatura quechua» es el texto donde Jorge Basadre materializa las ideas que tiene sobre la literatura inca. Me referiré a continuación a ese texto. Explica su preocupación por el idioma y explora si el quechua es un «idioma literario». Es obvio que su pregunta tiene una respuesta anclada en el positivismo, sin embargo, no es una afirmación absoluta. Establecida la demostración, indagará si existió una literatura inca. La primera pregunta que se plantea está vinculada al canon clásico, literatura asociada a la escritura, propone por ello que se la vea como una forma intermedia entre escritura y oralidad. Luego se plantea las siguientes observaciones: a) Esta literatura como un producto aristocrático, centrado en la casta gobernante, por lo que no tuvo posibilidades de divulgación masiva. Su circuito fue restringido; b) Estas formas ilustradas pasaron al silencio, allí se deformaron y se convirtieron en parte del patrimonio de la tradición oral. La ausencia de escritura no habría permitido el desarrollo de los géneros; c) Esto lo lleva a otro punto, ¿cómo documentar las producciones

La amabilidad de mi colega Miguel Ángel Rodríguez Rea hizo posible la lectura de ese texto. 
verbales prehispánicas? La documenta a partir de los cronistas primitivos; d) Luego se detendrá en la producción dramática, entre ellas incluye sus valoraciones sobre el Ollanta, El hijo pródigo, Usca Paucar y El pobre más rico, que representa la producción del renacimiento inca, en palabras de Bruce Mannheim y César Itier. Se detiene en el examen de la trayectoria del teatro.

Si el tema de la escritura lo asocia a una forma instrumental de la memoria como el quipu, necesita recurrir a otra categoría para completar su esquema, por eso la literatura inca la relaciona a la idea de folclor. Basadre plantea que «En los cantos y en los cuentos que conservan hasta hoy los indios se halla el bloque del 'folk-lore'.» (1939:27), le preocupa el tema de la imitación, por eso dirá que hay coincidencias. Luego, establecerá formas de realización discursiva inspirada en la propuesta que Anchorena registra en su Gramática quechua (1871).

Entonces, ¿qué entiende Jorge Basadre por literatura inca? Ciertamente su planteamiento sugiere una aristocracia del espíritu confrontada con el vulgo. Los incas representarían esa aristocracia; los indios, el vulgo. Para el compilador, la literatura inca estaría conformada por textos documentados en las crónicas, las investigaciones del siglo XIX, los manuscritos quechuas, la memoria de tradiciones cortesanas incas y la producción coetánea. No entrevé el proceso de la literatura quechua como diáspora entre la escritura quechua y las tradiciones orales en lenguas indígenas. Su preocupación por una definición normativa de literatura lo lleva a sugerir un concepto intermedio, dadas las dificultades que encuentra en el idioma y los medios de expresión como componentes básicos de ejercicio de cualquier literatura.

Desde una perspectiva romántica — la herencia del XIX — percibe al idioma quechua como lengua para expresar sentimientos, pero incapaz de trasmitir conceptos, abstracciones y expresiones morales. Se respalda en Beltrán y Tschudi. Carlos Felipe Beltrán sostenía, que un idioma para tener una «perfecta formación en sus versos» debería ser capaz de trasmitir lo que las culturas clásicas hacen. Consideraba que el quechua «no posee expresiones que pinten el mundo moral o intelectual, con la belleza de los idiomas sabios, no hay colores de todas gradaciones para presentar los cuadros de Homero, Virgilio, Dante, Petrarca, etc.» (cit. por Basadre: 9-10), mientras para Tschudi, «el quechua no se adapte(a) 
bien a la poesía». ${ }^{8}$ Ambos comparten una preocupación por los recursos retóricos, las estrategias discursivas no son las que corresponden al dominio de la lengua indígena, sino al armazón teórico de occidente. Es claro que el propio Basadre asume de manera ambigua lo planteado por Beltrán y Tschudi y no alcanza a entrever el mundo de las abstracciones, los juicios morales y los juegos del lenguaje en el idioma quechua, a pesar de los relatos, poemas y teatro que presenta en su compilación.

Basadre reconoce que «Es fácil argumentar que literatura viene de letra, es decir, que si no hay escritura no hay literatura propiamente dicha.» (11). Esto lleva a la discusión de un segundo tópico. Los medios de expresión literaria, por lo que propone entrever en los quipus una forma de inscripción literaria («Bien es verdad que como vehículo estrictamente literario, solo pudieron tener valor los quipus») ${ }^{9}$ y lo identifica con otro medio: «la creación literaria debió tener en gran abundancia el de la tradición oral» (10); aunque ésta será luego repensada dentro de la aristocracia del espíritu. Esto último permite a Jorge Basadre afincar su propuesta en el acervo cultural inca documentado en los cronistas, «los incas tuvieron un tesoro cultural más o menos rico», que, por cierto, lo distingue del folclore, toda vez que «Se trata de algo más coherente, intelectualizado, vigoroso e importante.» Este acervo tuvo como auxilio a los quipus. Siendo, así, nos propone que admitamos la existencia de una «pre-literatura», por eso dirá, «Aquí aceptaremos llamarla literatura» (11).

Si bien Literatura Inca resulta, como vengo sosteniendo una de las antologías más acabadas de la primera mitad del siglo XX, ésta en cambio reconoce su impronta instrumental, pues se trata de un texto de propaganda para el circuito letrado, cuya expectativa de lectores será el europeo, de allí su condición de texto exótico, emparentado con la lógica discursiva colonial. «Dióse a la obra el título 'Antología (sic) Inca' no sólo por el carácter sugerente que dicho nombre tenía que ofrecer en el extranjero, sino también por otras razones más.» Aun cuando se trate de una versión que va más allá de la incorporación de textos en quechua — como declara en su nota de 1939 - y cubre un espacio más vasto que el

Ver nota (1), se trata de una referencia a Viajes en el Perú, Tschudi (cf. BASAdRe 1938:10). Continúa: "porque los bastones con rayas son mencionados a propósito de documentos muy breves de tipo jurídico o administrativo; las pinturas corresponden más bien al arte pictórico y los petroglifos se relacionan con la epigrafía.» (BASADRE 1939:10). 
nacional, «cubre un ámbito territorial que teniendo como núcleo la sierra peruana» abarca la «acción difusora de los misioneros» de los siglos XVI y XVII (30-31).

En este contexto podemos imaginar una metáfora invertida del indio. El indio, será representado, en los términos que anoté en La literatura oral, ${ }^{10}$ como parte de un proceso que en pleno siglo XX lo convierte en un objeto decorativo, en un souvenir. Cuando se alude a inca sospechosamente se está reinventando un pasado glorioso y complaciente para castas enriquecidas del país, para los criollos. Ciertamente, el indio estaba de moda. El indio se trastoca, pues, en inca como representación escrita de la aristocracia.

\section{LITERATURA INCA}

De otro lado, podemos postular que en la propia génesis de este texto hay una tensión que vuelve a Literatura inca en un texto polémico desde el estudio de las ideas en el Perú, se trata de la ubicación de Basadre en el texto y de la compilación en el contexto de la producción cultural del país. El compilador del primer volumen de la Biblioteca de la Cultura Peruana se sitúa en un punto ambiguo y contradictorio; si bien se trata de una investigación de nivel, respecto al proyecto de Ventura García Calderón se subordina al punto tal que, casi, se inhibe de reconocer su propio texto: «Quien estas líneas escribe hubo de ayudarle en tan ardua tarea; y esta es la razón por la cual haya realizado las investigaciones que expone aquí, dentro de un campo que no es el de su trabajo habitual.»(:30) Basadre nos deja ver el resultado, pero no su voz a lo largo del texto; se ausenta, la voz que modela el texto es la de Ventura García Calderón que se instala en «Introducción General» y las notas que acompañan al volumen en mención. En el segundo caso, Literatura Inca, aparece como parte de un proyecto cultural marcado por los auspicios del gobierno de Óscar Benavides, ${ }^{11}$ y la figura aristocrática y criolla del

10 Ver «El concepto de literaturas orales/ Notas sobre los primeros 30 años del XX» (EsPINO 1999: 7-31).

11 «Biblioteca de la Cultura Peruana patrocinada por el señor General Oscar R. Benavides Presidente Constitucional de la República», reza la tapa del volumen publicada en 1938. Esta colección comprendió doce volúmenes, con una atención preferente por la literatura convencional, aunque con dos notables excepciones. Comprendió además de Literatura 
propio Ventura García Calderón. Se trata pues de un marco que supuso una imagen de la literatura, tal vez la más consistente serie, de la primera mitad del siglo XX. Literatura inca, resulta, en ese contexto, una propuesta de incorporación aristocrática al mundo letrado de los indios, de los quechuas.

El rigor aplicado por Jorge Basadre en esta selección es encomiable por dos razones, la primera porque pone nuevamente en circulación textos inaccesibles $\mathrm{y}$, dos, porque esa combinación entre la literatura quechua colonial y republicana, traducciones idóneas y la selección de recensiones críticas más importantes le otorga su vigencia. El libro asume una división convencional, tiene tres secciones: "Ficción y fábula", "Poesía” y "Teatro". En la primera sección básicamente se compila la narración de fuente indígena, incluye en ella textos recopilados por Adolfo Vienrich, Tarmapap pachahuarainin/Fábulas quechuas (1906); por Hildebrando Castro Pozo, Nuestra comunidad indígena (1924) y los de Arturo Jiménez Borja en Cuentos peruanos (1937). En todos los casos, no se incluyen las versiones quechuas, de manera que sólo se tienen las traducciones: además las versiones libres que se pueden leer en los tres autores citados. Esta sección, en su conjunto, proveen al lector las formas representativas de la tradición oral andina vigente. Conviene anotar, eso sí, la ausencia de los textos de Huarochirí, por lo menos en la versión de Francisco de Ávila, que ya era conocida en 1912, me refiero al Tratado y relación de los errores, falsos dioses y otras supersticiones... (1608). ${ }^{12}$

Inca, Los cronista de la conquista, una selección del Inca Garcilaso de la Vega, Los cronistas de convento, El apogeo de la literatura colonial. El lazarillo de ciegos caminantes. Los místicos. Costumbristas y satíricos. El importante Diccionario de peruanismos de Juan de Arona. Una selección de las tradiciones de Ricardo Palma y una antología poética de José Santos Chocano.

12 Conviene hacer notar que las versiones completas del Manuscrito de Huarochirí recién se conocen con los trabajos inaugurales de H. Trimborn, Dämonen und Zauber im Inkareich (Leipzig, 1939-1941) y la de Hipólito Galante, Francisco de Avila/ De priscorum hauruchiriensium origine et institutis (Madrid, 1942). Para una lectura literaria, Dioses y hombres de Huarochirí (Lima, 1966), traducida por José María Arguedas y para una lectura filológica, precisa del Manuscrito remito a Ritos y tradiciones de Huarochiri (1987) preparada por Gerald TAYLOR. Sobre el Tratado, ver: Francisco de Ávila: Tratado y relación de los errores, falsos dioses y otras supersticiones y ritos diabólicos en que vivían antiguamente los indios de las provincias de Huarocheri, Mama y Chaclla y hoy también viven engañados con gran perdición de sus almas en Dioses y hombres de Huarochirí (Lima, Museo Nacional de Historia - Instituto de Estudios Peruano, 1966) pp. 198-217. La versión paleográfica corresponde a Sybila Arredondo. 
En lo que se refiere a la sección "Poesía", se presentan poemas coloniales y contemporáneos, sólo algunos de estos traen la traducción. Reproduce los textos de Santa Cruz Pachaccuti quien consigna la «Oración de Manco Capac», que al ser estudiados a partir de la filología quechua, se trata de adaptaciones del catecismo católico en la escritura quechua (cf. Itier: 198). Incluye acertadamente los recogidos por Huamán Poma de Ayala en su Nueva Corónica... Luego aparecen los canciones recopiladas por el propio Basadre, aunque con título que sugiere la percepción de la alquimia del espíritu «Cantos folklóricos del quechua»(:96) recopila dos taki cusqueños: «Pukuy-pukuy» ${ }^{13}$ el cual resulta un aporte, pues permite documentar las lecturas sobre esa ave emblemática que en los relatos sureños representa al indio y explica el trauma de la conquista y el consiguiente desplazamiento de los indios. Luego incorpora textos bolivianos y ecuatorianos; el libro vuelve a poner en circulación dos poema paradigmáticos: «Cheqajchu Urpi...?/ Es cierto paloma» atribuido a Juan Wallparimachi y «Adiós del indio» de Luis Cordero, debe anotarse que la traducción al castellano la realiza J. M. B. Farfán. Luego incorpora los «Cantares quechuas» que había recopilado Alomías Robles, no se incluyen las versiones quechuas que proceden de Cajamarca, Ancash, Cuzco y Puno. En la misma sección aparecen los trabajos que Vienrich reproduce en la antología de 1905, me refiero a Tarmap Pacha Huaray/Azucenas quechuas, no se publican las versiones quechuas. Continúa con una selección de 30 textos publicados en La musique des Incas et ses survivences (1925) de los Harcourt, no se copia las canciones quechuas ni las partituras. Aparece luego «La sabiduría de Pachacutec» incluida en los Comentarios reales, así como un relato «Nací como lirio en el jardín», reproducido por Pedro Sarmiento de Gamboa. Tal vez la ausencia mayor esté referida a los cantos religiosos católicos que tienen una hibridez inspirada en la cultura prehispánica o son modelos de inspiración indígena, como el caso de Hanan pacha kusinin de Bertonio.

La sección "Teatro" muestra el entusiasmo de Basadre. Afirmativamente había anotado que la literatura inca ha tenido en el teatro sus mejores realizaciones: «Ese carácter de mezcla entre oratoria, poema épico y representación dramática debió tener, en la mayoría de los casos, el llamado teatro de los Incas. Sobre las representaciones escénicas mismas, no cabe duda.» (1939: 12-13). En realidad se

13 Los esposos Harcourt habían publicado, en 1925, un texto referido al mismo tópico, me refiero a Pukop pukop kesampicus (BASADRE 1938: 123). 
trata del renacimiento inca, o mejor dicho, de la época de oro del teatro quechua, cuyas formas están vinculadas al teatro del siglo de oro español, aunque la imaginaría andina hace pasar las marcas hispanas como plegadas e insospechables de hispanismo, aparentan ser propiamente indígenas. Constituyen la más importante producción de la aldea letrada quechua (Mannheim 1999, Itier 1999, Espino 2001). Esta sección combina los textos con la crítica. «Una joya de la literatura keswa escrita en el siglo XVI / Yauri Tito Inca o El pobre más rico» (1937) de Humberto Suárez abre la sección. Junto a la traducción de Ollanta, pone al lector en algunos comentarios que ubican el debate ollantino de fines del XIX, me refiero a los trabajos al «Prólogo» (1886) firmada por F. Pí y Margall; la «Introducción» y el «Análisis del drama bajo el punto de vista histórico. Examen de detallado de sus escenas» (1878) ambos de Pacheco Zegarra; y, la «Crítica de E. W. Middendorf de la traducción de Ollanta de Pacheco Zegarra» (1890). Incluye, finalmente, la «traducción directa [del alemán] y a menudo literal» de Federico Shwab de un libro inhallable, me refiero a E. W. Middendorf Dramatische un Lyrishe Dichtungen der Keshua-Sprache (1891), ningún texto quechua se traslada en la compilación de Basadre. Incluye El hijo pródigo, Usca Páukar y las 50 «Poesías modernas», entre las que destacan una versión de «Manchay puytu» con el título «La gruta del horror» (Elegía N. ${ }^{\circ} 43$ ) y «La viuda», un texto de fines del XVIII. Finaliza la antología con la inclusión de un anexo que da cuenta de la memoria de la tradición ollantina. Pero no se detiene en el teatro contemporáneo que el examina en su ensayo de 1939, me refiero a la trayectoria del teatro de Usca Maita de Mariano C. Rodríguez y Sumac Tica de Nicanor Jara. ${ }^{14}$ Un texto ausente, es sin duda, el referido a la Muerte y fin de Atahualpa.

\section{VIGENCIA DE LA LITERATURA QUECHUA}

No hay duda que la selección de Jorge Basadre concluye un ciclo en la literatura peruana vista desde la inclusión andina. Ese período es la pugna por consignar un espacio para la choza en el solar. El mundo indígena se posesiona de una

14 Para una revisión del teatro cuzqueño se puede revisar el trabajo de Cesar ITIER, El teatro quechua en el Cuzco (Cuzco, CBC-IFEA, 1995) Sobre los trabajos de Beltrán, revisar las notas de CÁCEREs (1987). 
palabra autorizada e ingresa al mundo de la escritura, aunque en la versión de la metáfora invertida, del indio convertido en inca. Este ciclo en la escritura concluye con los esfuerzos de Adolfo Vienrich, Hildebrando Castro Pozo y los esposos Harcourt, que desde miradas solidarias o exóticas, en ese contexto impresionista de la época, el indio está de moda, aparece o es aceptado en la medida que remita a la noción inca, circulará en el espacio letrado del poder y como artefacto exótico en París.

La vigencia de Literatura Inca podemos indagarla a partir de la producción más importante que tiene lugar luego de su publicación. Ese mismo año José María Arguedas da a conocer Canto Kechwa (1938), libro que cuestiona el estereotipo según el cual el indio es triste. Inmediatamente después hay un silencio casi cómplice. Aparecen los estudios sobre la Muerte del inca Atahualpa de Lara y Meneses. Jesús Lara quien invierte tiempo y posibilidades en este esfuerzo, nos entrega su compilación Mitos, cuentos y leyendas quechuas (1952).

En el plano local, Francisco Izquierdo Ríos y José María Arguedas ofrecen una compilación que da cuenta de una versión integradora de las regiones, que hoy día se ha convertido en un referente necesario para los estudios sobre la cultura oral peruana, me refiero a Mitos, leyendas y cuentos peruanos (1947). J. M. B. Farfán publicará su Colección de Textos Quechuas del Perú (1952), aunque está contagiado por la necesidad de explicar, en el caso del quechua, sus realizaciones dialectales; aun cuando deja entrever como centro de atención el arte verbal quechua. Jorge A. Lira edita su Canto de Amor (1956), en que deja traslucir la palabra quechua como ejercicio poético. Sergio Quijada Jara recopila en la región central los textos quechuas vinculados al pastoreo en Canciones del ganado y pastores (1957). Más tarde vendrá la antología publicada Poesía y prosa quechua (1964) por la Biblioteca Universitaria de Francisco Carrillo, luego aparece la edición del Ollanta preparada por Sebastián Salazar Bondy y J. M. Arguedas. Pero ninguna de estas publicaciones presentó lo que Jorge Basadre llamó «una antología indígena peruana con criterio integral.» (1939: 30).

En las últimas tres décadas del siglo XX se puede documentar trabajos más audaces, y casi completos. La década del 80 fue la más intensa e interesante, entre ellos debemos indicar a la Literatura quechua (1980) de Edmundo Bendezú Aibar, incluye sólo textos poéticos y narrativos quechuas traducidos al castella- 
no. Luego vendrá esa imagen casi completa que hay en Teatro quechua colonial (1983), antología prepara por Teodoro Meneses. La Poesía aborigen y tradicional popular (1984) preparada por Alejandro Romualdo, que básicamente recoge la tradición escrita quechua, no sólo letrada sino también la proveniente de la tradición oral, así como los escritores quechuas modernos. En ese contexto aparece la restitución de diversos textos quechuas, como ocurre con el trabajo de los Montoya La sangre de los cerros/ Urkunapa Yawarnin (1987) y es también una actualización de la producción de Efraín Morote Best, Aldeas sumergidas (1988). De hecho los 90 significa la recuperación de varios autores quechuas y de inspiración indígena, entre ellos, en lo que narrativa quechua se refiere, Cuentos de Alto Urubamba (1990) de Jorge A. Lira. Luego, podemos anotar, la Poesía quechua escrita en el Perú (1993) antología preparada por Julio Noriega Bernuy y La voz del trueno y el arco iris (2000) que presenta la literatura quechua escrita y la tradición oral de Huancavelica, trabajo elaborado por Isaac Huamán Manrique. Todo esto sólo para dar cuenta de un importante segmento de difusión del impacto de la producción quechua indígena y de la tradición escrita.

Todos estos textos han ido actualizando nuestra memoria, pero aún no alcanzan a ofrecer esa mirada de cierre de un ciclo y de presentación totalizadora que encontramos en Literatura inca. Aunque es preciso indicar que en este mismo tercio de siglo constituyó la apertura, conocimiento y difusión de las textualidades étnicas del país, en particular, de la Amazonía, sobre todo los realizados desde el Centro Amazónico de Antropología y Aplicación Práctica (CAAAP), y de otro lado, la aparición de trabajos cuidadosos, frescos y confiables, sobre las literaturas producidas por los quechuas campesinos y aymaras (Kay pacha o Literatura y cultura aimara). Publicada en el contexto de revuelta indigenista, Literatura inca asume un titulo imposible, arcaico había sido utilizado en el siglo XIX - ; concluye un ciclo e inaugura uno nuevo que aún no ha culminado. Resulta, finalmente un libro ambiguo en el contexto en que se publica y simultáneamente sublevante, aun cuando la metáfora del indio esté trocada en inca. 
AllPanchis. 1987: Lengua, nación y mundo andino. Sicuani, Cuzco (Allpanchis N. ${ }^{\circ}$ 29-30 Año XIX).

Arguedas, José María (1938). Canto Kechwa. Con un ensayo sobre la capacidad de creación artística del pueblo indio y mestizo. Lima, Ed. Horizonte, 1989.

1986: Cantos y cuentos quechuas. Lima, Munilibros.

. (y) Francisco IzQuierdo Ríos. (1947) Mitos, leyenda y cuentos peruanos. 2. ${ }^{\text {da }}$ ed. Lima, Casa de la Cultura del Perú, 1970.

Ayala, José Luis. 2002: Literatura y cultura aimara. Con textos bilingües aimara-castellano. Lima, Universidad Ricardo Palma.

BASADRE, Jorge (comp.). 1938: Literatura Inca. Selección de Jorge Basadre. Introducción General de Ventura García Calderón. París, Brouwer (Biblioteca de Cultura Peruana, Primera Serie 1).

1939: «En torno a la literatura quechua» en Sphinx III, N. ${ }^{\circ} 4-5$. Lima, marzo-junio, pp. [7]-37.

1928: Equivocaciones: ensayos sobre literatura. Lima. Historia de la República del Perú. 1822-1933. 8. ${ }^{\text {va }}$ ed. Lima, La República-Universidad Ricardo Palma, XVIX.

Beltrán, Carlos F. 1880: Civilización del Indio, Antología sagrada en español, quechua y aymará, Oruro.

1888: Civilización del Indio, Ramillete hispano-quechua, original con multitud de poesías originales y antiguas mejoradas, Cuzco.

Bendezú, Edmundo. 1980: Literatura Quechua. Caracas, Biblioteca Ayacucho. 2. ${ }^{\text {da }}$ ed. Lima, Universidad Ricardo Palma, 2003.

CÁceres Romero, Adolfo. 1987: Nueva Historia de la Literatura Boliviana, Literaturas Aborígenes. La Paz, Cochabamba, Ed. Los Amigos del Libro. CArrillo, Francisco (Comp.) Poesía y prosa quechua (1964?) Prólogo de José María Arguedas. 2. ${ }^{\text {da }}$ ed. Lima, Biblioteca Universitaria, 1968. 1967: Teatro quechua. El hijo pródigo-Usca Páukar. Lima, Biblioteca Universitaria.

Dedo CRítico. 2002: «Los mejores libros de la crítica literaria peruana del siglo XX», Dedo Crítico, revista de literatura, año VIII, N. ${ }^{\circ}$ 9, Lima, octubre 2002; pp. 93-99. 
D’Harcourt, Roul (y) Marguerite. (1925): La música de los incas y sus supervivencias. Lima, Occidental Petroleum Corporation of Perú, 1990 ( La musique des Incas et ses survivances).

EsPino Relucé, Gonzalo. 2003: «Las literaturas peruanas del siglo XIX y la aldea letrada quechua» en Ajos \& Zafiros N. ${ }^{\circ}$ 5, revista de literatura. Lima, 2003; pp. [77]-85.

2001: «La aldea letrada quechua: Literatura quechua en el espacio de la literatura canónica del siglo XIX» en Escritura y Pensamiento, año IV, N. ${ }^{\circ} 8$, revista de la Unidad de Investigación de la Facultad de Letras y Ciencias Humanas, Universidad Nacional Mayor de San Marcos. Lima; pp. 101-114.

1999. Imágenes de la inclusión andina. Literatura peruana del XIX. Lima, Instituto de Investigaciones Humanísticas-Universidad Nacional Mayor de San Marcos. 1999. La literatura oral o la literatura de tradición oral. Quito, Abya Yala Editores.

FARfán, J.M.B. 1952: Colección de Textos Quechuas del Perú. Lima, Instituto de Estudios Etnológicos, Sección Lingüística (Revista del Museo Nacional, tomos XVI-XX).

Huamán Manrique, Isaac.2000: La voz del trueno y el arco iris. Literatura de Huancavelica. Lima, Pachakuti Editores.

Itier, César. 1992. «Lengua, ideología y poder en el Cuzco: 1885-1930» en El quechua en debate, comp. Juan Carlos Godenzzi (Cuzco, CBC, 1992); pp. $25-48$

1991. «Un drame du XIXe siècle en quechua cuzquénien: Yawar Waqaq d'Abel Luna» en Cultures et Sociétés Andes et Méso-Amérique. Melanges en hommage à Pierre Duviols. Provence, Université de Provence, 1991, t. 1; pp. 478-499.

LARA, Jesús. 1969: La literatura de los quechuas. Ensayo y antología. 2. da ed. La Paz, Lib. Ed. Juventud.

(1947): La poesía quechua. $1 .^{\text {ra }}$ reimp. México, Fondo de Cultura Económica, 1979.

LiRA, Jorge A. 1956: Canto de Amor. Recogido y traducido por Jorge A. Lira. Cuzco.

1990: Lira, Jorge A. Cuentos de Alto Urubamba Cuzco, Centro Bartolomé de las Casas. 
ManNHeim, Bruce. 1999. «El arado del tiempo: Poética quechua y formación nacional» en Revista andina 33. Cuzco, año 17- N. ${ }^{\circ}$ 1, julio 1999; pp. 15 -64.

MARIÁtegui, José Carlos. (1928): 7 ensayos de interpretación de la realidad peruana. 5. ${ }^{\text {ta }}$ ed. Lima, Imprenta Editorial Amauta, 1988. (Obras completas, Biblioteca Amauta N. ${ }^{\circ}$ ).

Markham, Clements R. 2001: Cuzco and Lima. Lima, Petroperú Ed.

Martos, Marco. 1998: «Anales de la Inquisición de Lima. Ricardo Palma, la vela verde y el sambenito», en Escritura y Pensamiento, N. ${ }^{\circ} 2$. Lima, 1998, pp. 213-235.

Matto de Turner, Clorinda. 1888: «El Qquechua y su utilidad» en El Perú Ilustrado: II: 69: 302-303. Lima ( $1^{\circ}$ de septiembre 1888$)$. $1888^{\mathrm{a}}$ : «El Qquechua y su utilidad» en El Perú Ilustrado: II: 76: 330-332 (Lima, 15 de septiembre de 1888). . 1887: «Estudios históricos [El qquechua...]» en $L a$ Revista Social: III: 116: 295-296 (Lima, 8 de octubre de 1887). [Después del título: «A la Sociedad 'Arqueológica Lingüística', este texto fue leído una semana antes de su publicación en el Círculo Literario y fechado, «Lima - 1887»].

Meneses, Teodoro. 1983: Teatro quechua colonial. Lima, Edubanco. (Incluye facsímil del Códice de Ollantay, del Convento de Santo Domingo). 1961. «Estudios Ollantinos / Clasificación de fuentes». Sphinix: N. ${ }^{\circ}$ 14: pp. 80-100 (Lima. II época).

MerA, Juan León (1892): Cantares del pueblo ecuatoriano. Guayaquil, Publicaciones Educativas Ariel, 197?, 2 tt.

Middendorf, Ernst. W. (1890): Gramática Keshua. Trad. Ernesto More. Madrid, Ed. Aguilar, 1970. [Das Runa-Simi oder Keshwa-Sprache wie sie gegerwärting in der pronvinz Cuzco geschprochen wird, 1890/Die Einheimischen Sprachen Perus]

1891: Dramatische und lyrische Dichtungen der Keshua Sprache (sic). Leipzig, F. A. Brockhaus.

MontoyA, Rodrigo, Edwin y Luis. 1987: La sangre de los cerros/ Urkunapa Yawarnin. Lima, CEPES - Mosca Azul - UNMSM.

Morote Best, Efraín. 1988: Aldeas sumergidas. Cuzco, Centro Bartolomé de las Casas. Noriega Bernuy, Julio.1993: Poesía quechua escrita en el Perú. Antología. Lima, Centro Estudios y Publicaciones (CEP). 
QuIJADA JARA, Sergio. 1957: Canciones del ganado y pastores. Lima, P. Villanueva. RIVET, Paul - Georges de CRÉQUI-MONTFORT. 1951-1952: Bibliographie des langues Aymará et Kicua, 1540-1875. París, Institut d'Ethnologie.

Romuldo, Alejandro.1984: Poesía aborigen y tradicional popular. Lima, Edubanco (Poesía Peruana Antología General, t. I)

Torero, Alfredo. 1974. El quechua y la historia social andina. Lima, Universidad Ricardo Palma.

VIENRICH, Adolfo. 1905: Tarmap Pacha Huaray/Azucenas quechuas. Tarma, La Aurora de Tarma, 1905. 3. ${ }^{\text {ra }}$ ed., Lima, Ed. Lux, 1999.

VILLARÁN, Acisclo. 1874. «La poesía en el Imperio de los Incas / Ensayo histórico. Dedicada en muestra de gratitud al eminente literato D. Eduardo Asquerino» en El Correo del Perú. Lima enero-abril, 1874. 